\title{
LA IMAGEN AL SERVICIO DE LA LITERATURA
}

\author{
Aleix Cort y Cori Pedrola ${ }^{1}$
}

RESUMEN: El artículo mostrará el largo viaje realizado hasta el momento por la palabra y la imagen a través de los siglos para incidir en la importancia de conocer la historia como forma de avanzar hacia el futuro.

PALABRAS CLAVE: Palabra. Imagen. TIC. VideoLit.

En nuestra cultura, la visión parece ser el sentido que goza de mayor credibilidad. Por todos es sabido la vieja cantinela de que vale más una imagen que mil palabras. Quizás sea cierto, pero no es menos cierto el hecho de que para explicar esas imágenes necesitamos palabras. Es realmente difícil concebir un mundo sin palabras. Gracias a ellas, creamos imágenes y el mundo toma la condición del nombre que le otorgamos, así es que hay que cuidarlas e incidir en su valor.

La palabra y la imagen llevan muchos años acercándose, colaborando, en esculturas, pinturas, poemas visuales, caligramas, manuscritos, anuncios publicitarios, performances, instalaciones, distintas muestras de lo que ha acabado siendo conocido como literatura digital (distinto de la literatura digitalizada), algunos formatos de artes escénicas, etc. La posibilidad de desarrollar la creatividad a través de la literatura parece una buena alternativa para insistir en la importancia de la palabra y de la propia literatura más allá de los libros.

Paralelamente a la llegada de las TIC y al desarrollo de internet, han ido creciendo y desarrollándose diferentes formatos que subrayan la importancia de los libros y de la literatura desde distintas plataformas y con distintas intenciones. Dos de los más importantes son a nuestro parecer, en estos momentos, el booktráiler y el videolit. Nacidos con distinta intención (el booktráiler nació como un recurso publicitario para

\footnotetext{
1 Aleix Cort: Grupo de Investigación Hermeneia y "Máster de Literatura en la Era Digital". aleix.cort@gmail.com. Cori Pedrola Grupo de Investigación Hermeneia y "Máster de Literatura en la Era Digital", Universitat de Barcelona. coripedrola@gmail.com.
} 
vender libros, mientras que el videolit nació como una posibilidad de utilizar la literatura como semilla creativa con proyección audiovisual), han acabado encontrándose en las aulas.

Actualmente, prevalece lo efímero, la velocidad, la no linealidad, y este cambio afecta a una actividad como la lectura y, por extensión, al sistema escolar, pero también a la creatividad en general. La historia se ha acelerado a un ritmo tan vertiginoso que los cambios son constantes y las instituciones (como la escuela) y las empresas (editoriales) sufren para intentar adaptarse a esos cambios. Este dinamismo afecta tanto a la cultura como a la educación y el ocio. Dentro de este nuevo marco, formatos como el videolit o el booktráiler tienen un largo camino para recorrer. El artículo mostrará el largo viaje realizado hasta el momento por la palabra y la imagen a través de los siglos para incidir en la importancia de conocer la historia como forma de avanzar hacia el futuro.

Palabras clave: Palabra. Imagen. TIC. VideoLit.

\section{Una imagen nunca valdrá mil palabras, ni viceversa.}

En una cultura como la nuestra, parece ser que el sentido que goza de mayor credibilidad entre nosotros es el de la vista. Por todos es conocida la socorrida cantinela de que vale más una imagen que mil palabras. El dicho es cierto, sin duda, pero no es menos cierto que para explicar esas imágenes necesitamos las palabras. Tampoco, que hay palabras que contienen mil imágenes. Los antiguos tenían clarísimo la importancia del lenguaje y los griegos no dudaron de atribuir a Hermes (un mensajero) el origen de lenguaje y de la escritura. De ahí, conceptos como hermenéutico o "Hermeneia", un grupo de investigación del que formamos parte, interesado en la interpretación de los textos literarios y sus especificidades en el medio digital. 


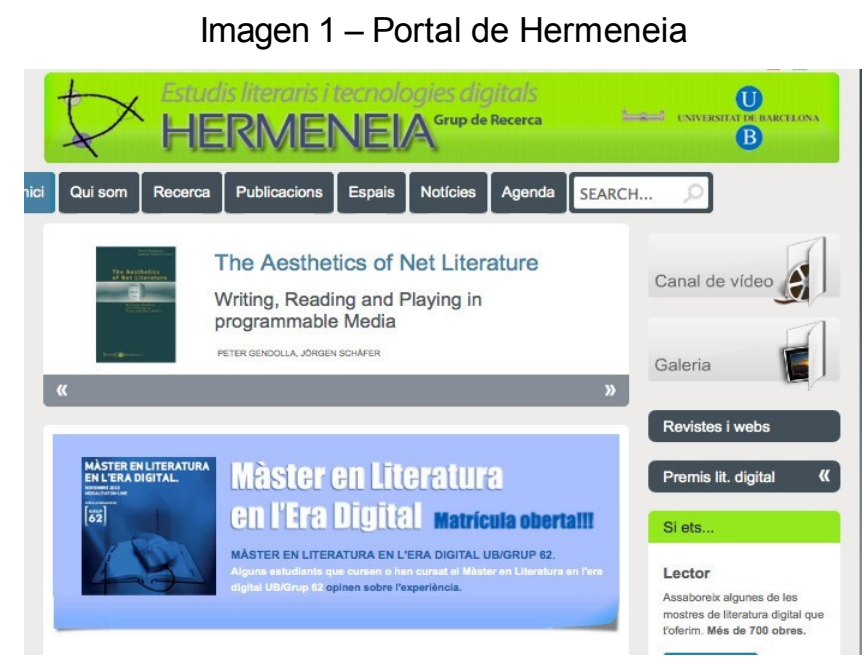

Identificar los elementos estratégicos que constituyen la estructura de los textos digitales: infografía de las imágenes, poética de sus elementos, (il)legibilidad del mensaje o las relaciones que se producen en ese contexto entre imagen y texto, es un reto excitante y los resultados de esta investigación pueden ayudar a comprender el mundo en el que estamos inmersos. Para ello, pero, es interesante aprender a "ver" las palabras y a "leer" las imágenes.

Imagen y texto: breve recorrido a través del tiempo

El proceso de hibridación entre la palabra y la imagen tiene una larga historia. Tenemos constancia de esta comunión a través de esculturas, monedas, caligramas, miniaturas medievales, pinturas, manuscritos, anuncios publicitarios, performances, distintos formatos escénicos y algunas muestras de lo que ha acabado siendo conocido como literatura digital. 
Imagen 2 - Jeroglífico egipcio. [lzquierda] Dibujo de Wang Mingming (segle XX) y poema de Liu Yuxi (s VIII-IX). [Derecha] Simmias de Rodas: "Alas" (300 aC).

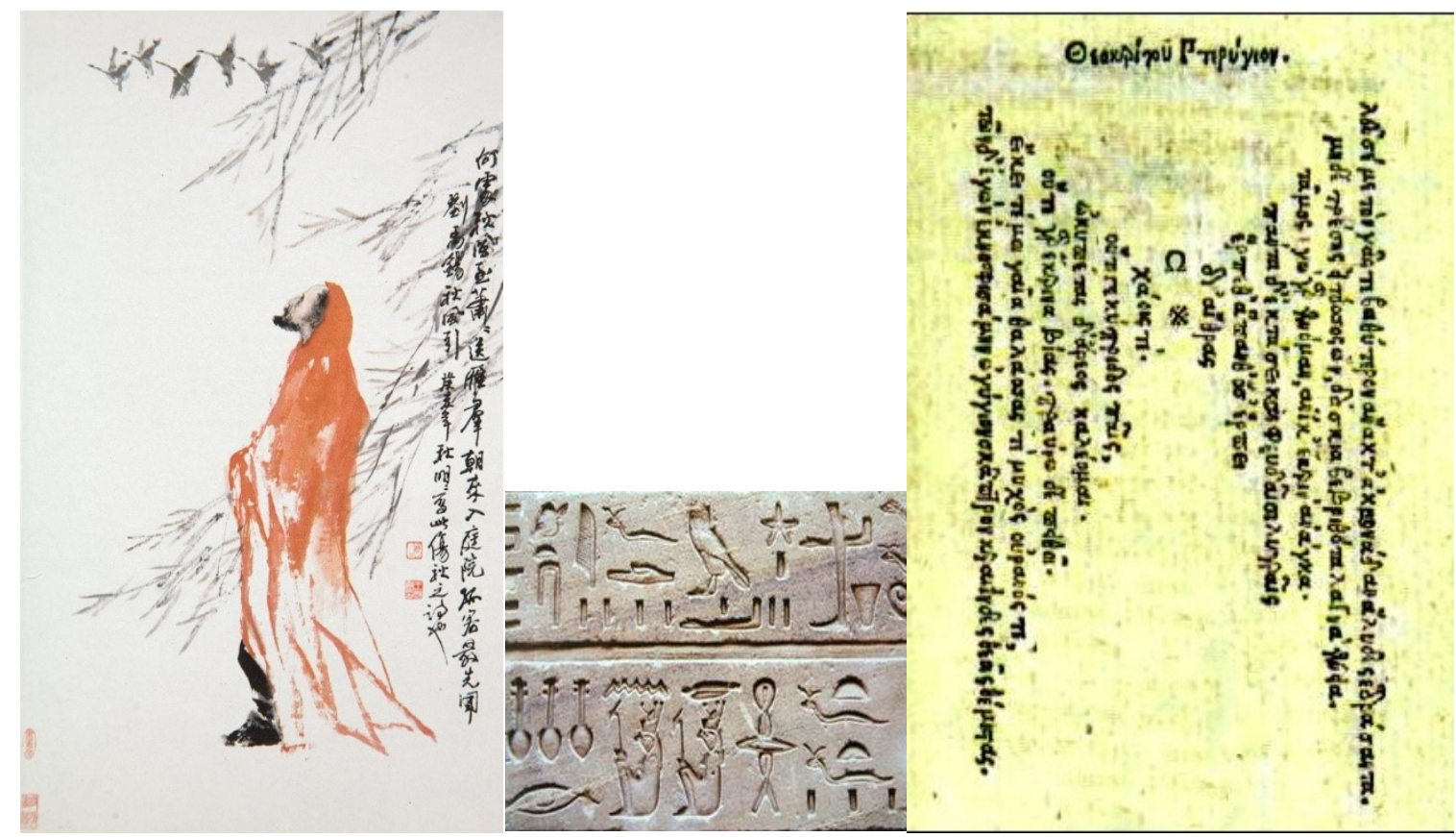

Imagen 3 - Beato de Liébana Ars Magna (735-798); Rabano Mauro (s. IX); Miniatura del de Ramon Llull realizada por Thomas le Myésier (d.1321)
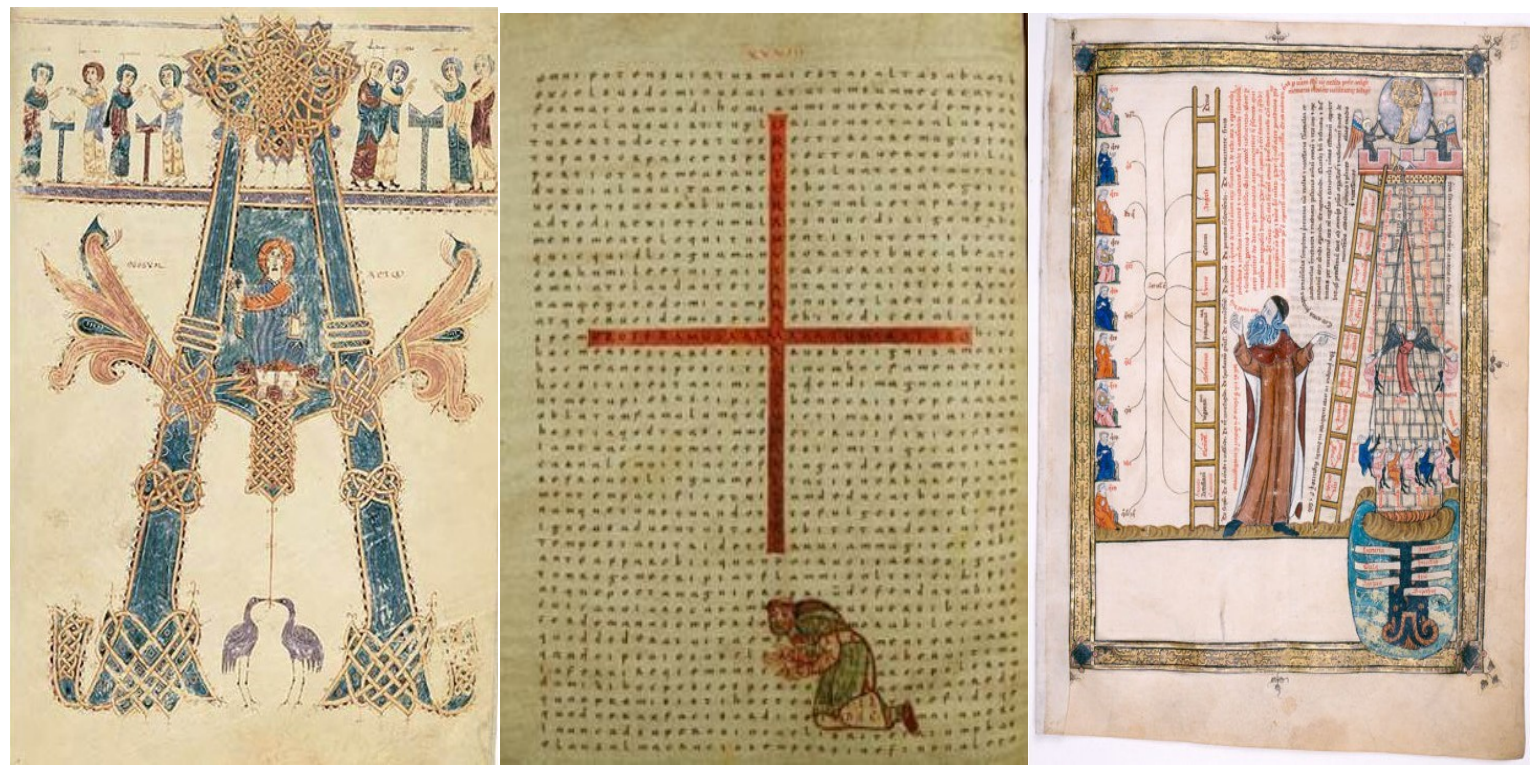

Texto Digital, Florianópolis, Santa Catarina, Brasil, v. 11, n. 1, p. 173-193, jan./jun. 2015. ISSNe: 1807-9288. 
Imagen 3 - José de Ribeira "La mujer Barbuda" (1631); Tommaso Marinetti "Les mots en libertés" (1915) ; Guillame Apollinaire "Il pleut" (1918).
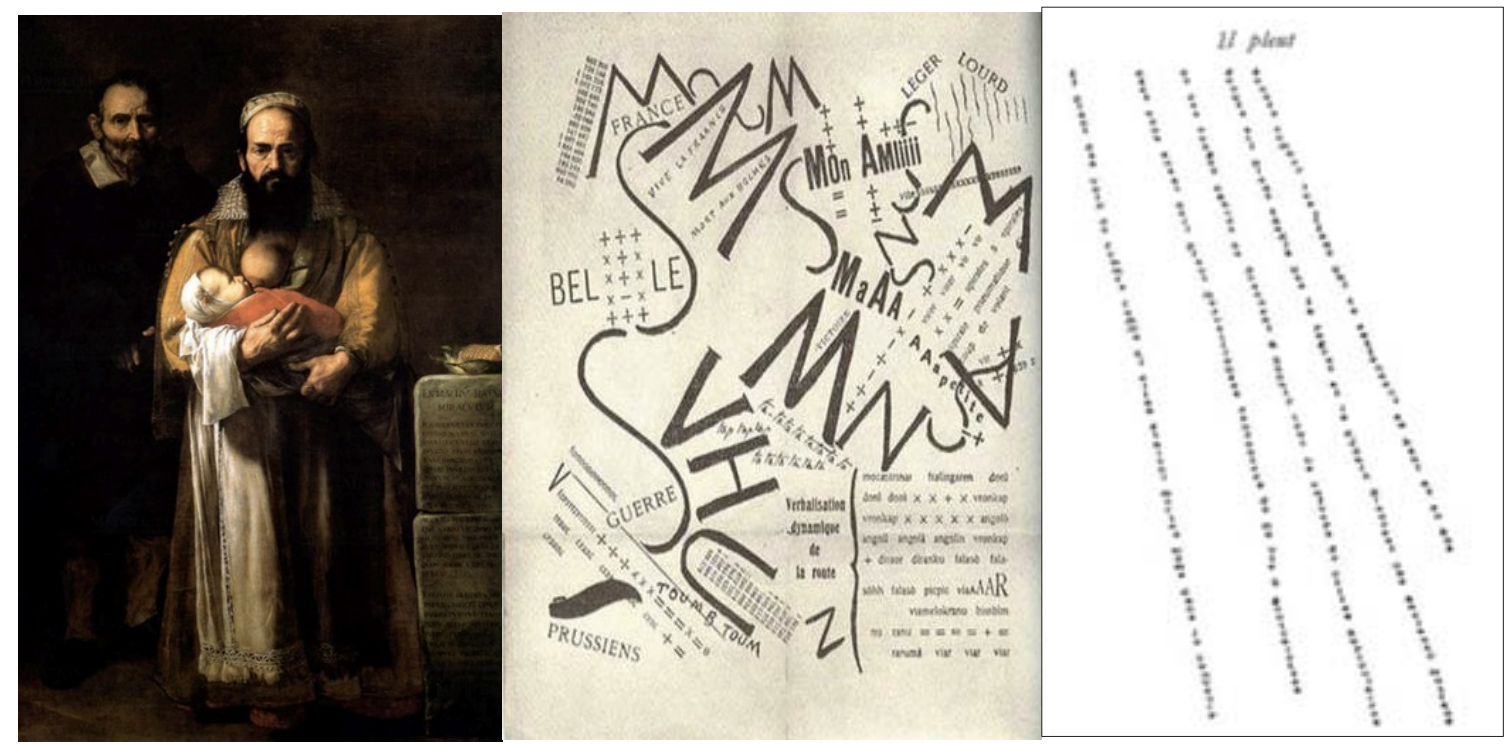

Imagen 4 - Joan Miró: "Un oiseau persuit une abeille et la baisse" (1927-1937); Walker Evans: "Damaged" (New York City , 1930).

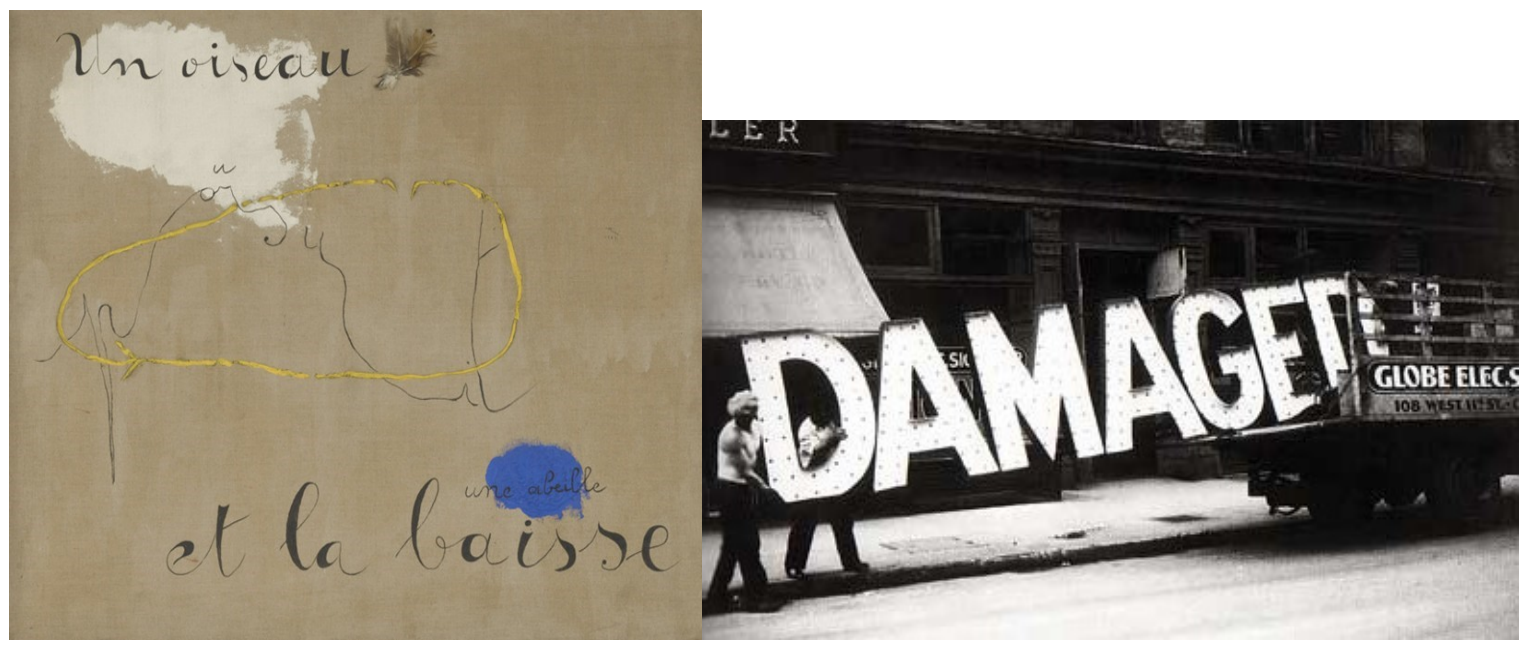


Imagen 5 - Isidore Isou “Les journaux des Dieux" (1950); Joan Brossa "Poema” (1970-1978).

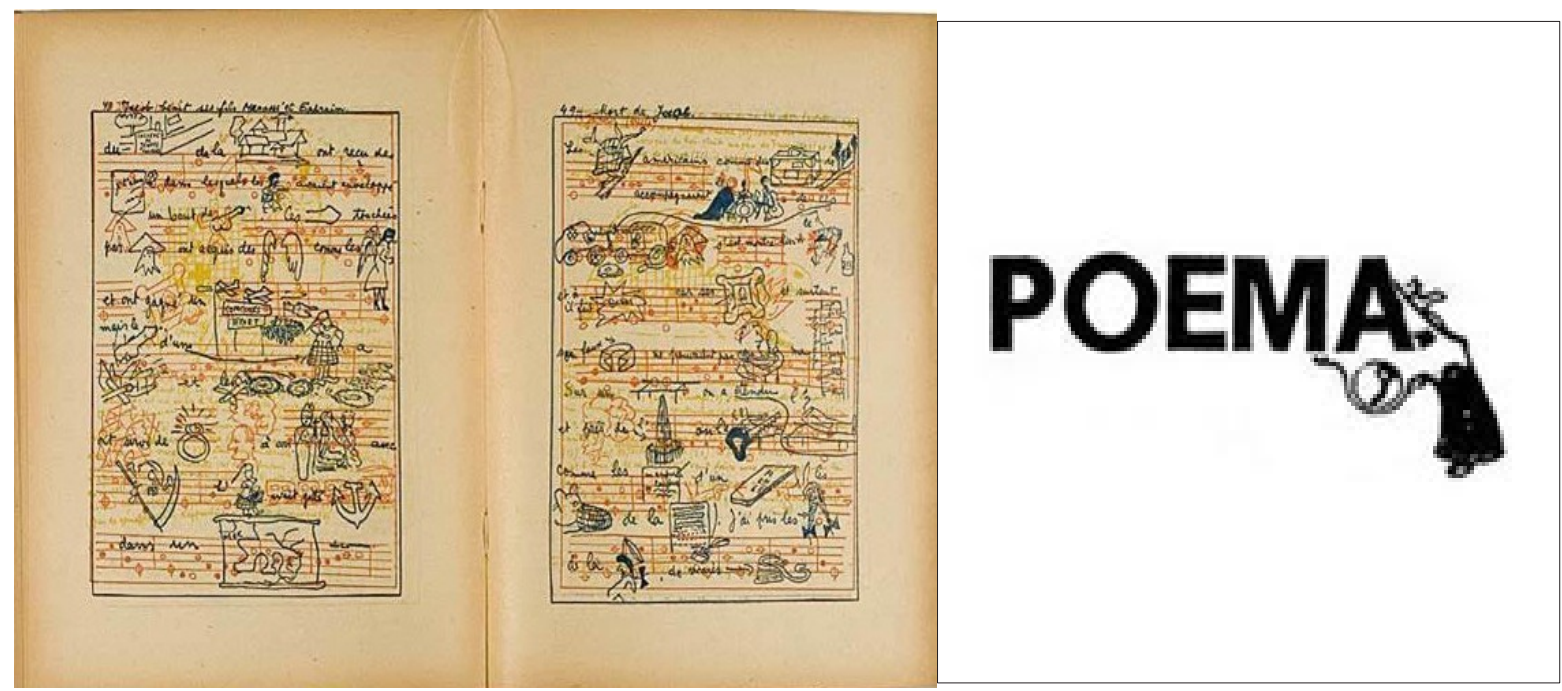

Imagen 6 - Jenny Holzer: "Protect me from what I want" (Truismo, 1983-1985); Shirin Neshat: "Untitled" (De la sèrie "Women of Allah", 1993).

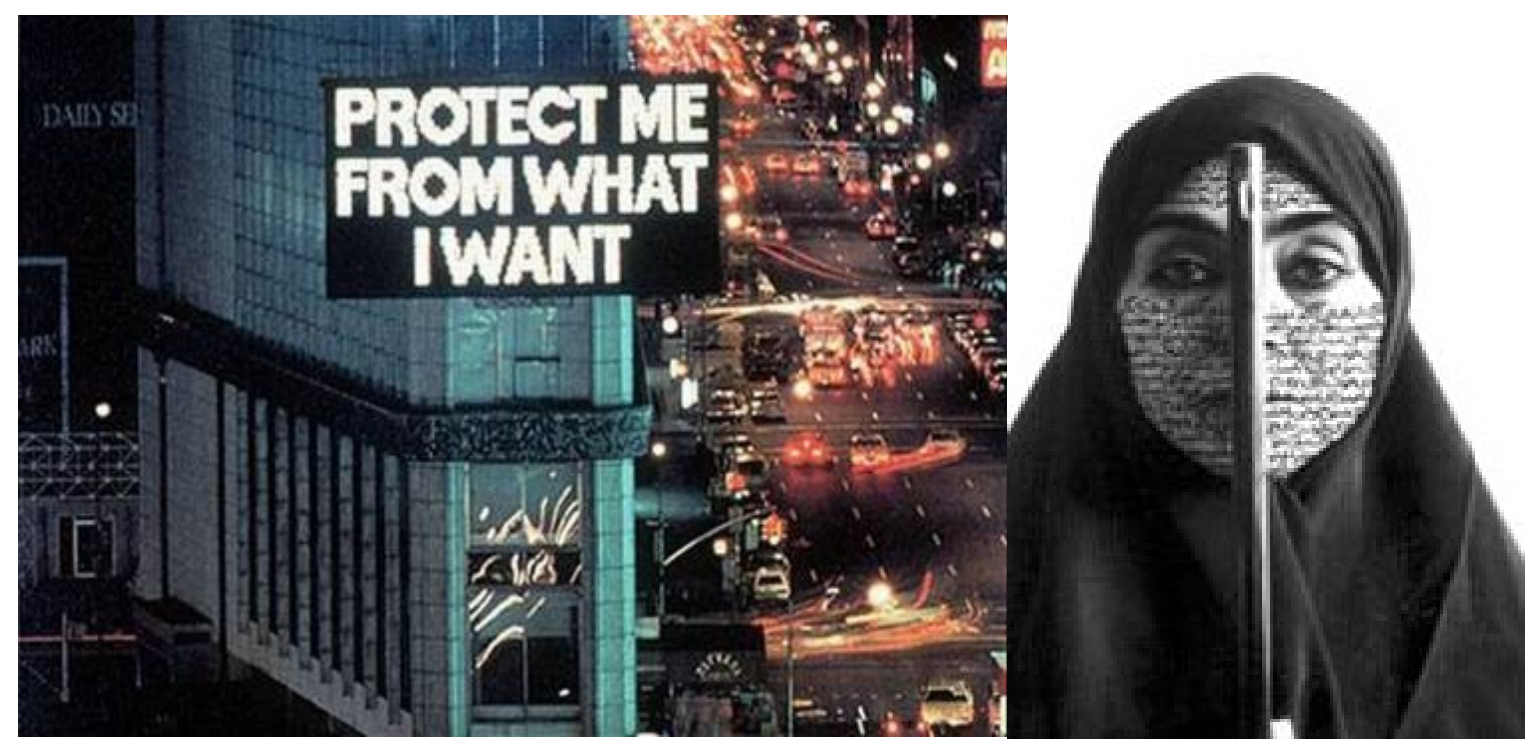

Texto Digital, Florianópolis, Santa Catarina, Brasil, v. 11, n. 1, p. 173-193, jan./jun. 2015. ISSNe: 1807-9288. 
Imagen 7 - Alex Gopher: "The Child” Director: Antoine Bardou-Jacquet ${ }^{2}$ (1999); Camille Utterback y Romy Achituv "Text Rain" (1999)

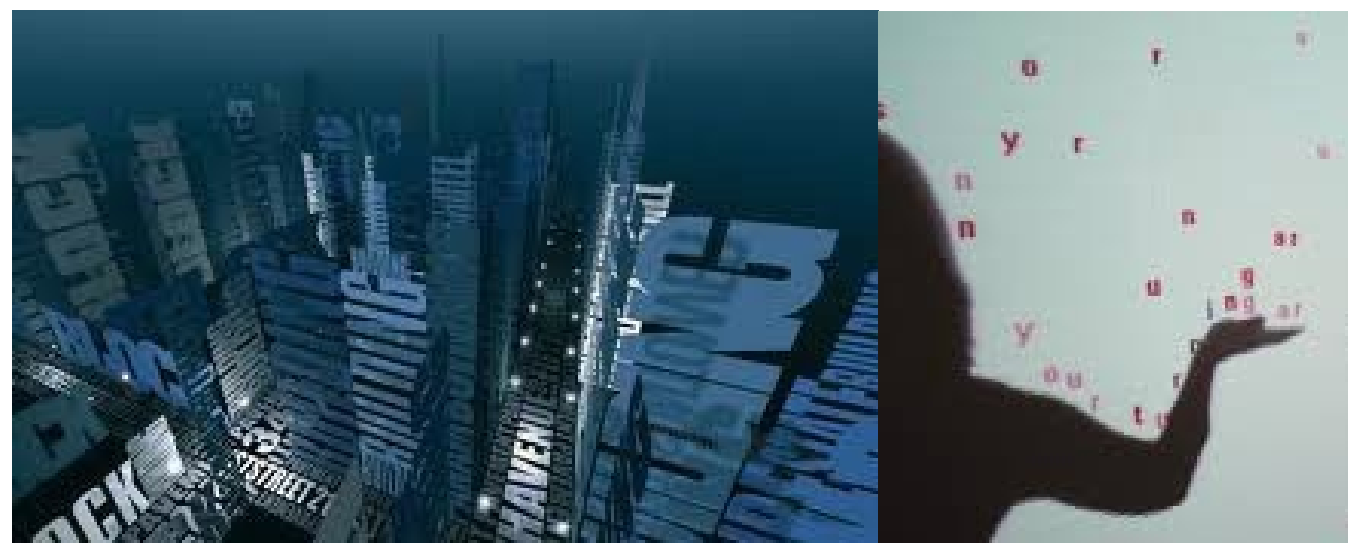

Imagen 8 - Barry Threw amb Noah Wardrip-Fruin-Robert Coover: "Screen" (CAVE, 2007); Portal del proyecto Poetry beyond text: poesía, visión y conocimiento ${ }^{3}$

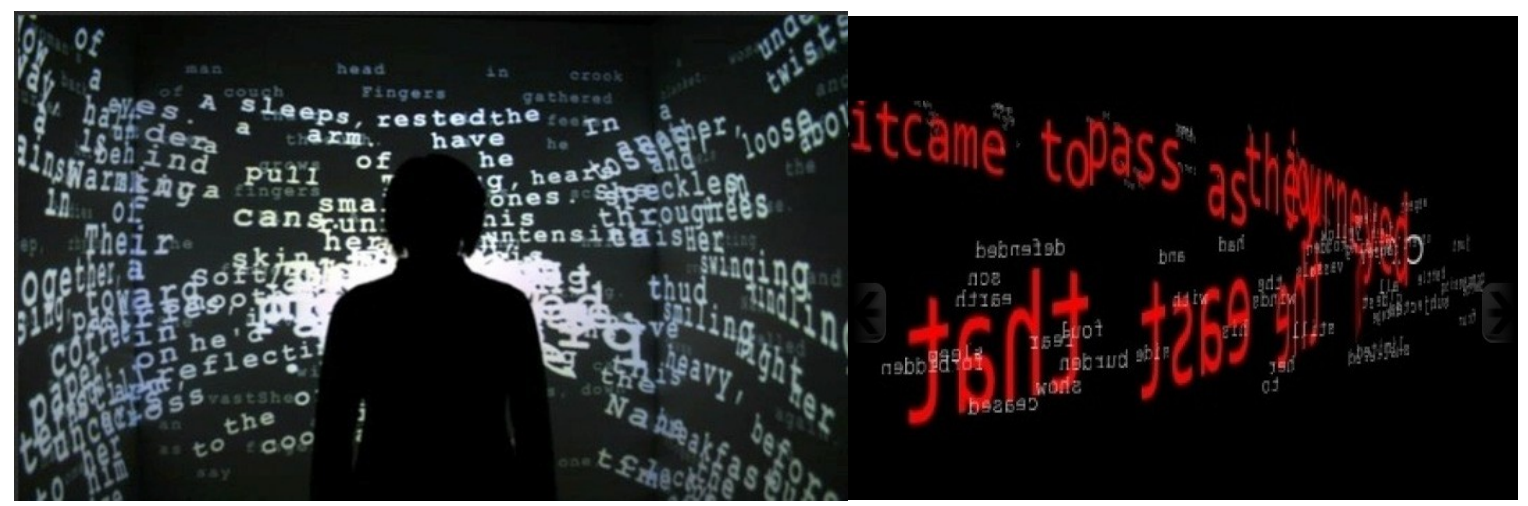

En estos momentos coinciden en las pantallas cápsulas que utilizan el poder de la palabra como recurso publicitario ${ }^{4}$ (ASICS), cápsulas en las que la literatura sirve para hacer publicidad de un producto que no tiene nada que ver con la literatura ${ }^{5}$ (LEVIS), y cápsulas en las que una historia sirve para publicitar los libros y la lectura a través de las palabras ${ }^{6}$.

\footnotetext{
2 "The Chid": <http://videolit.org/pg/videolist/watch/6685>.

${ }^{3}$ Poetry beyond text: <http://www.poetrybeyondtext.org/biggs-shovman.html>.

${ }^{4}$ Campanya de ASICS de 2011, una continuació de la de 2010: https://www.youtube.com/watch?v=As2-MDMTWvk

${ }_{5}$ El nuevo anuncio de Levis 501 parafrasea una parte de Midsummer Night's Dream, de William Shakespeare, para que sus consumidores potenciales identifiquen el producto como algo exclusivo y diferente al resto: <https://www.youtube.com/watch?v=CsuxuSAgMSY; https://www.youtube.com/watch?v=XPyD4jyiObo $>$.

${ }^{6}$ Anuncio de Randhom House construido como una aventura: $<$ http://videolit.org/pg/videolist/watch/6515>.
} 
Imagen 9 - Anuncio de ASICS; Anuncio de LEVIS.

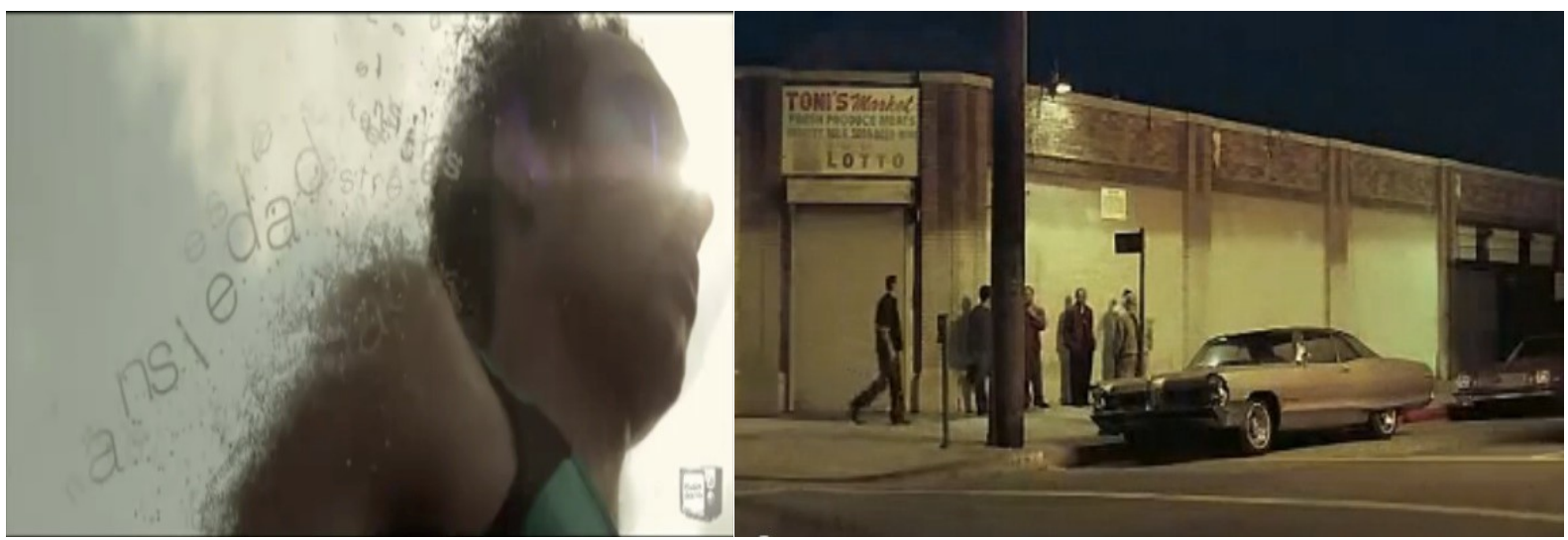

Imagen 10 - Anuncio de Randhom House: "Me gusta leer"; Anuncio de Wimbledon

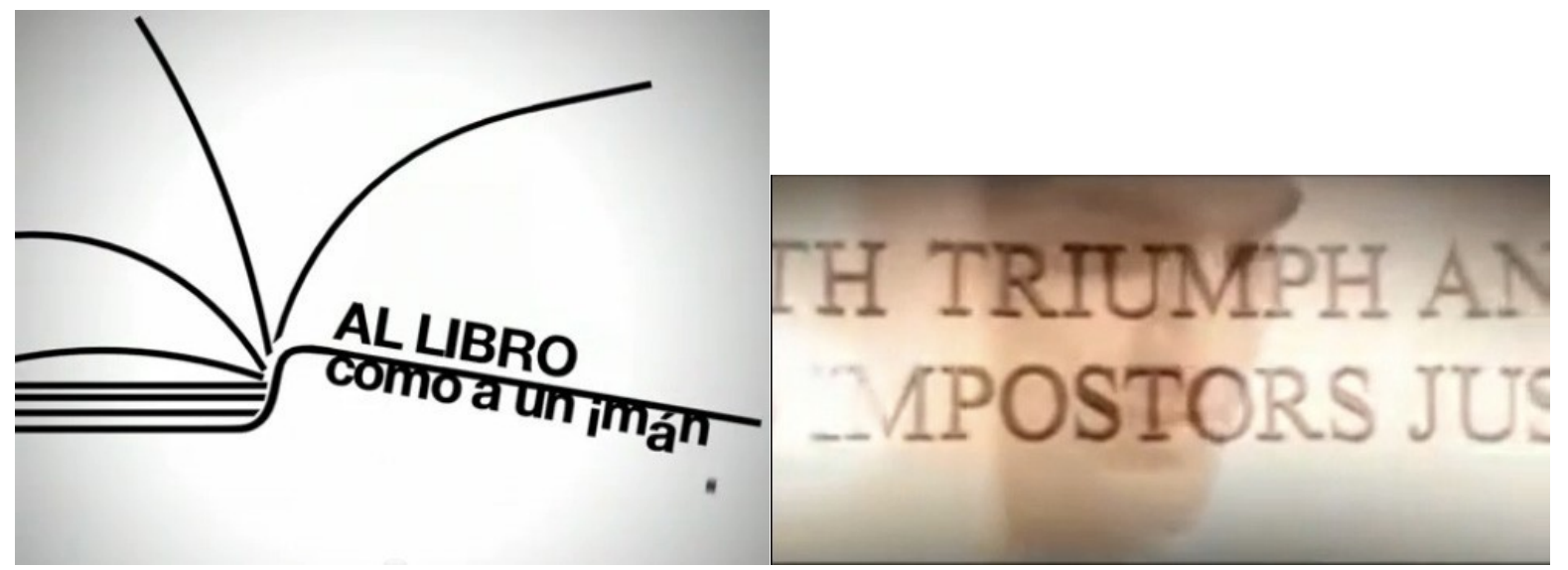

Pero también propuestas que utilizan la literatura a nivel creativo (instalaciones, espectáculos de danza, esculturas y diferentes formas de narrativa audiovisual) y formatos y metodologías como el videolit, que la utilizan a nivel educativo (literatura, lengua, visual y plástica, lengua extranjera). En todos esos casos es fundamental ser consciente del valor de la palabra y de la imagen y del valor de este encuentro, un encuentro que proyecta la literatura más allá de los libros ${ }^{7}$.

Imagen y texto: Algunas consideraciones.

En la actualidad, existen distintos tipos de relación entre la imagen y el texto: imagen con texto como pie de foto, textos que forman parte de una imagen y textos con valor

\footnotetext{
${ }^{7}$ Anuncio de Wimbledon a partir de "If ", un poema de Rudyard Kipling leído por Nadal y Federer: $<$ https://www.youtube.com/watch?v=vEeLh5ltQcY>.
}

Texto Digital, Florianópolis, Santa Catarina, Brasil, v. 11, n. 1, p. 173-193, jan./jun. 2015. ISSNe: 1807-9288. 
de imagen. Algunas de las experiencias en las que hemos tenido el placer de participar (concursos y talleres realizados en institutos, escuelas de arte, universidades, museos, bibliotecas y centros culturales) han partido, precisamente, de estas relaciones y de algunas de las posibilidades que aportan, especialmente, aquellas que están relacionadas con el soporte audiovisual (una de cada tres horas de Internet se dedican a al visionado de cápsulas audiovisuales).

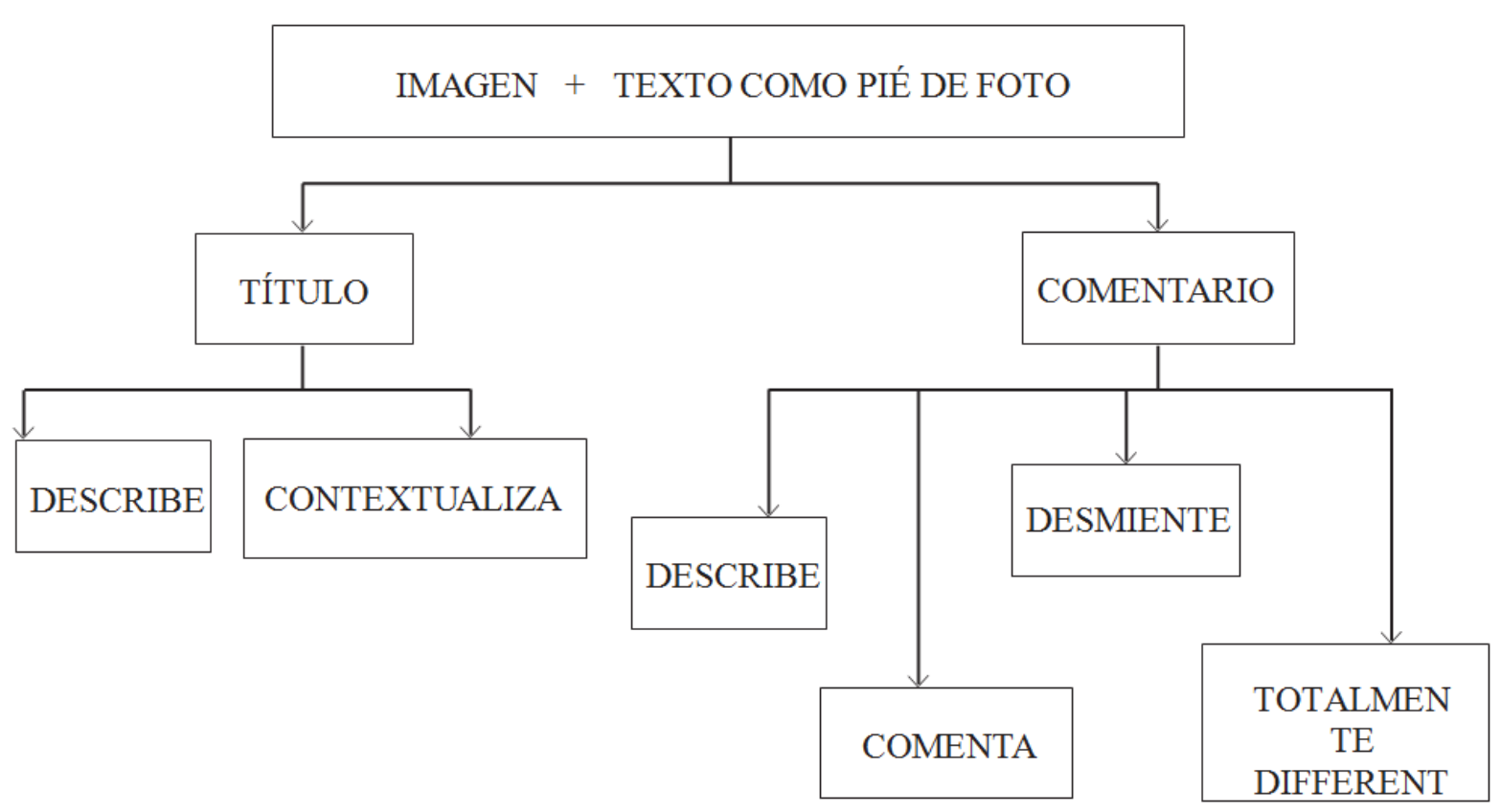

Algunos estudios realizados en torno a este consumo ${ }^{8}$ concluyen que un vídeo no es nunca sustituto del entorno de recomendación ni de las opiniones, reseñas o contraportadas que puedan generar una lectura, pero avalan este tipo de soporte para promocionar servicios a través de la Red, ya que según estos mismos estudios ${ }^{9}$ las personas que ven un vídeo de un producto son más propensos a comprar el producto anunciado y las ventas adicionales que acarrean que los que no lo ven.

Así las cosas, no es extraño que Internet se haya convertido en un gran escaparate

\footnotetext{
8 "Un reciente estudio..." es un estudio sobre el consumo del vídeo en la red: <http://marketingactual.es/index.php/internet/205>. El estudio confirma el imparable crecimiento del consumo-de video online.

${ }^{9}$ El book trailer, el millor pla per connectar llibres i lectors", de Gabriel Pena i Ballesté, resume algunas de las ventajas que aporta el booktrailer a la hora de promocionar la venta de un libro: $<$ http://libredigital.blogs.uoc.edu/2013/05/28/el-book-trailer-el-millor-pla-per-connectar-llibres-ilectors/>.
} 
para las empresas orientadas al modelo B2C (Business-to-Consumer): ver, seducir, aconsejar y satisfacer. Tampoco, que la publicidad en medios convencionales haya empezado a perder peso a favor de esos espacios temáticos en la red. Dos de las razones de este cambio de tendencia las podemos encontrar en la universalidad de Internet y su accesibilidad. Cualquier producto o servicio se puede promocionar en ese espacio, aunque es importante tener en cuenta que la tendencia de la demanda es pedir vídeos cortos y de calidad y que es conveniente distribuirlos en espacios temáticos y para un público objetivo.

Desde esta perspectiva, la fórmula Internet + booktrailer puede suponer una oportunidad para algunos de los libros que pasan prácticamente desapercibidos; mientras que la de Internet + videolit puede ser utilizada para incidir en la importancia de la literatura más allá de los libros y para dar a conocer

el trabajo de los alumnos y sus intereses. La Red permite cuantificar estos visionados: saber dónde se ha visto un video, quien lo ha visto, cuanto tiempo ha estado mirándolo y el resultado de esta visión (impacto social, educativo o económico). La idea de que la cultura y la literatura - como parte de aquella - es un lujo es, pues, un error que sólo alguien sin perspectiva de futuro se puede permitir. La cultura "vende" (aunque no sea ese su objetivo fundacional) y es, a la vez, un océano de inspiración más allá

de los libros. La red está llena de ejemplos que ratifican una evidencia que algunos gobiernos parecen decididos a seguir ignorando.

\section{Booktrailer y Videolit. Diferencias y similitudes.}

Paralelamente a la llegada de las TIC y al desarrollo de internet, han ido desarrollándose diferentes formatos que subrayan la importancia de los libros y de la literatura en distintas intenciones. Más allá de lo que se conoce actualmente con el nombre de "narrativa transmèdia", dos de los formatos que presentan mayores posibilidades de evolución a nivel creativo, educativo y divulgativo, y con un largo 
camino aun por recorrer, son el videolit y el booktrailer.

Imagen 11 - Tráiler de "La ladrona de libros".

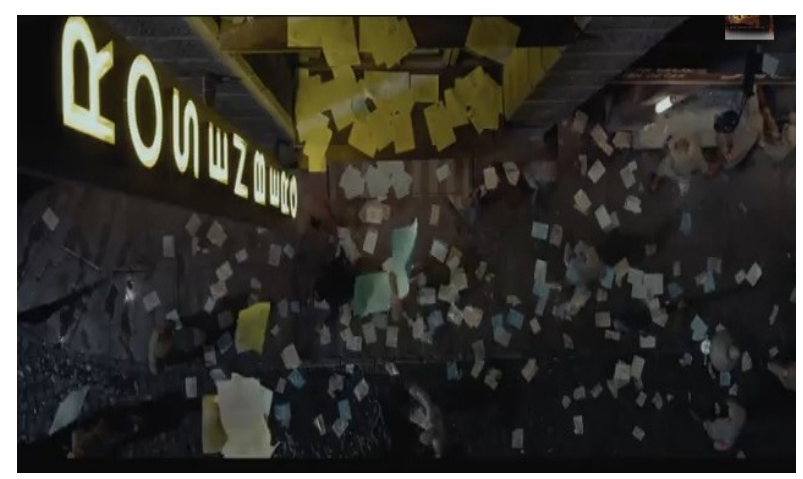

Si el tráiler ${ }^{10}$ es una cápsula de promoción cinematográfica que se realiza con imágenes y sonidos de la película que presenta; el booktráiler, es un video que actúa como soporte de la campaña de promoción de un libro empleando técnicas similares a la de los tráilers cinematográficos (actores, vídeos, animación, fotografías...) para transmitir los aspectos más atractivos del libro sin revelar la trama. Su función es incitar a la lectura y es válido para todos los géneros: poesía, narrativa, ensayo, biografías, libros de divulgación, manuales... ${ }^{11}$

Imagen 12. Booktrailer de "Word as image"12; Booktrailer de "Luces en el canal".

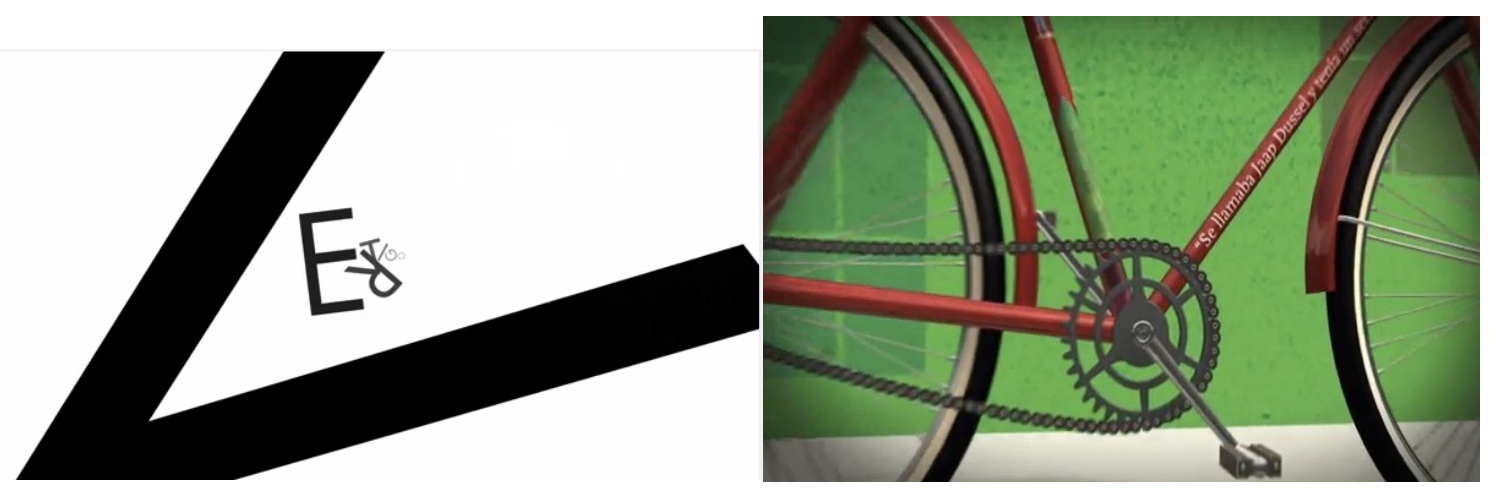

\footnotetext{
${ }^{10}$ Originalmente, los tráilers se mostraban al final de las proyecciones de los largometrajes que se proyectaban (de ahí su nombre: "remolque"); actualmente, suelen mostrarse antes de la película principal para promocionarla. Imagen del tráiler correspondiente a uno de los últimos best sellers llevados al cine: La ladrona de libros de Markus Zusak: <https://www.youtube.com/watch?v=qrFeM$\mathrm{x} 2 \mathrm{k}-\mathrm{s}>$

${ }^{11}$ Booktrailer realizado por un profesional dedicado al libro "Luces en el canal" de David Fernández Sifres, Premio El Barco de Vapor, 2013: https://www.youtube.com/watch?v=FGZ8vqlpBPY

${ }_{12}$ Resulta interesante ver el booktrailer realizado por Bran Doughrty-Johnson para promocionar el libro de Ji Lee: "Word as image", utilizando los elementos gráficos de las letras de cada palabra sin añadir elementos externos.
} 
El booktrailer aparece en Estados Unidos a finales de la década de los noventa y llega a España en 2006. Desde entonces, su estilo se ha ido haciendo cada vez más heterogéneo: vídeo-entrevista al autor o editor, video para captar el interés del futuro lector-comprador, video con recomendaciones de los lectores o agentes del sector literario, etc.

Avanzando por caminos similares al del booktrailer tenemos el videolit ${ }^{13}$, un formato que forma parte actualmente de los contenidos que se imparten en el Máster de Literatura en la Era Digital de la Universitad de Barcelona, con una larga experiencia ya en las aulas de distintos centros educativos y dos acepciones distintas recogidas en el Wikcionario:

- Cápsula audiovisual que parte de un texto literario.

- Metodología de aprendizaje activo a través de un proyecto de creación artística ${ }^{14}$.

El videolit tiene voluntad de transversalidad y multidisciplinariedad al explorar los límites del arte a través de las nuevas tecnologías, incorpora el fenómeno literario como semilla creativa y, como metodología de aprendizaje, incide en la importancia de la creación como fuente de ocio e instrumento del crecimiento intelectual, permitiendo explorar diferentes sistemas de representación y diversas áreas del conocimiento (artes visuales, literatura, música, tecnología).

\footnotetext{
${ }^{13}$ El videolit es creado como formato audiovisual por Aleix Cort el año 2004 (marca registrada). El año 2005 se presenta públicamente en distintos festivales. El año 2008 empiezan las colaboraciones con distintos centros educativos, jornadas, seminarios y congresos, y juntamente con Cori Pedrola se desarrolla el videolit como metodologia de aprendizaje activo a través de un proyecto de creación artística.

${ }^{14}$ Videolit: http://es.wiktionary.org/wiki/videolit
} 
Imagen 13 - Videolit dedicado a Joan Vinyoli; Videolit "Una il-lusió de paper"

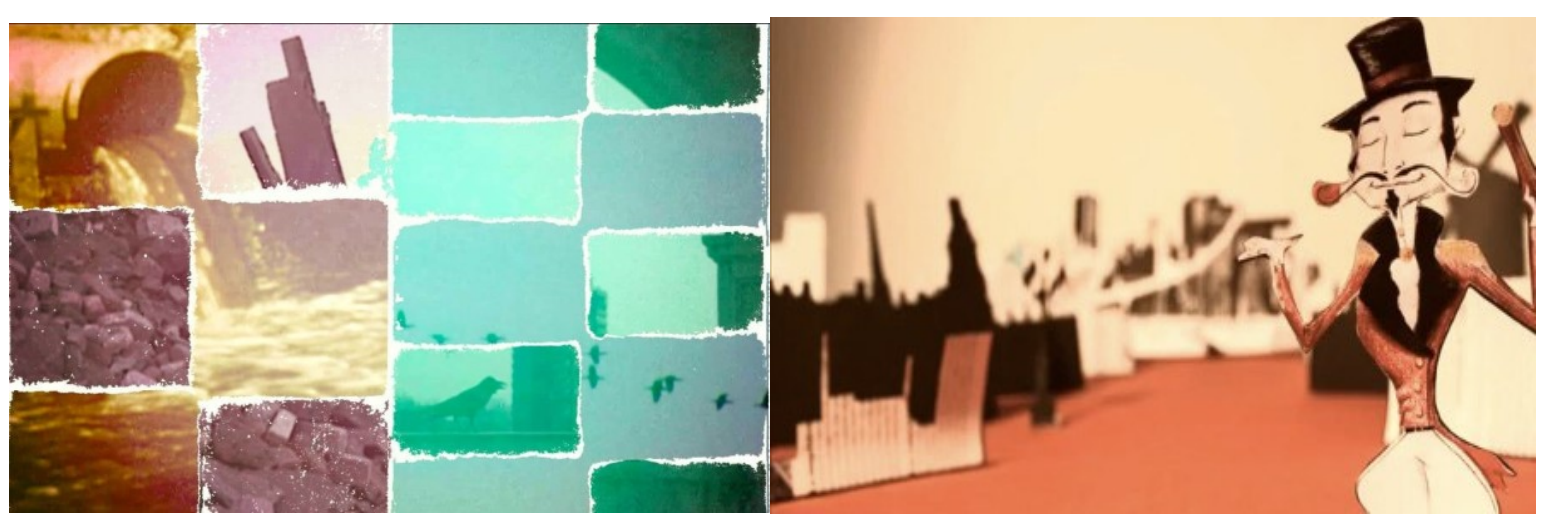

El videolit avanza en tres líneas diferentes que se complementan y superponen: la creativa, la educativa y la divulgativa ${ }^{15}$. Distintamente al booktrailer, el objetivo del videolit no es nunca vender un "producto" sino el de incidir en el poder de la palabra y de la literatura como simiente creativa y como recurso educativo ${ }^{16}$.

\section{Videolit: Metodología y objetivos}

Actualmente, los principales objetivos de los formatos audiovisuales que utilizan la literatura son la venta y la educación. El entretenimiento es un valor añadido que posibilita una mayor empatía por parte del comprador o del alumno, pero un formato que parta de la idea de entretener para incitar a la lectura está aún por explorar, aunque empiezan a haber algunos proyectos que parten de un material literario para convertirlo en fuente de entretenimiento. En ningún caso, pues, deberemos perder de vista la permeabilidad de las fronteras entre formatos y géneros.

\footnotetext{
${ }^{15}$ Videolit realizado por Aleix Cort y Toni Espinosa como homenaje al poeta Joan Vinyoli (2014) con el apoyo de la Institució de les Lletres Catalanes.

16 "Una ilusión de papel" es uno de los videolits realizados por los alumnos de la Escola d'Art i Disseny de Reus con el apoyo de los departamentos de tecnología, arquitectura efímera y arte de la escuela, a partir del cuento "Carrers de paper" (Camaleotròpiques, A. Cort) durante el taller "Transitar la paraula": <https://www.youtube.com/watch?v=rOVJ3xLHXqc>.
} 
Imagen 14 - Booktrailer de "Blood's a Rover"; Videolit "Peus i estrelles".

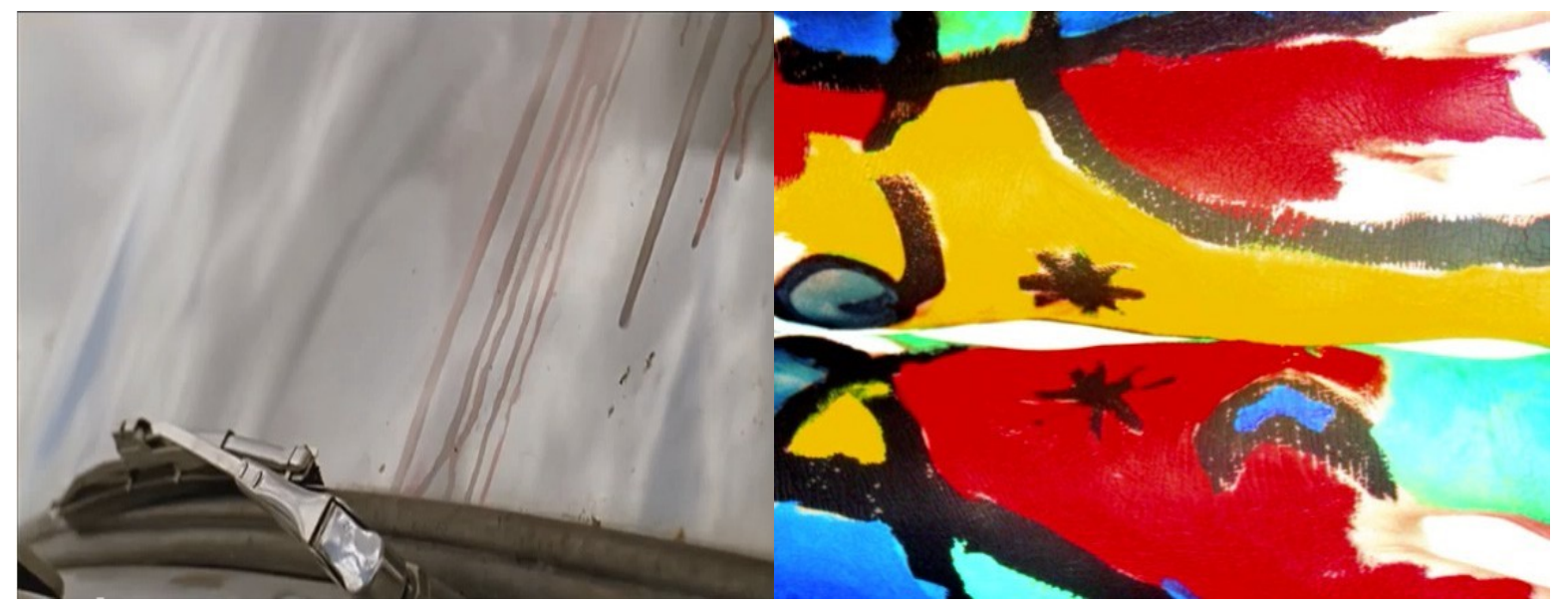

Queda claro, pues, que la principal diferencia entre booktráilers ${ }^{17}$ y videolits no está tanto en el formato como en su origen e intención: mientras que el booktrailer está pensado y construido, en principio, para captar lectores-compradores, el videolit nace como una cápsula creativa y se amplía como metodología educativa ${ }^{18}$. Además, y esto es fundamental, el videolit sólo tiene razón de ser si su material de base es la literatura mientras el booktrailer se sustenta sobre una obra que no tiene porqué ser literaria $^{19}$.

Por sus características, el videolit y el booktrailer pueden ser utilizados en el terreno educativo, especialmente, si la metodología sobre la que sustentan su trabajo es del aprendizaje activo a través de un proyecto artístico, un tipo de metodología que comprende un conjunto de estrategias de aprendizaje que involucran a los estudiantes en proyectos complejos y del mundo real a través de los cuales pueden desarrollar y aplicar sus habilidades y conocimientos. La metodología que proponemos para el videolit en los cursos y talleres que impartimos, cumple esta premisa y tiene como objetivos:

- Constatar que hay literatura más allá de los libros.

\footnotetext{
${ }^{17}$ Booktrailer realizado por estudiantes de The National Film and Television School para al libro Blood 's a Rover de James Elroy (último, de la trilogía "Underworld USA"), ganador de "The Book Video Awards 2010" en la sección Crime \& Thriller: <https://www.youtube.com/watch?v=HN6EEcpTLNo>.

18 "Peus i estrelles" es un videolit realizado por Bonet y Casulla durante el taller que realizamosdurante las IV Jornadas Pedagógicas organizadas por el Museo de Arte Moderno de Tarragona a partir de la obra de Miró y de su relación con JV Foix.

19 The 4-Hour Body de Timothy Ferrisa (Harmony Books), es un libro sobre dietas: $<$ http://www.youtube.com/watch?v=LIVmsIJyj3A>.
} 
- Valorar la literatura y el arte como parte fundamental de la cultura de nuestro tiempo.

- Fomentar el respeto por la palabra y la imagen.

- Reflexionar sobre las relaciones que se establecen entre arte, literatura y comunicación.

- Desarrollar una actitud de interés por la obra que se presenta.

- Vertebrar un trabajo interdisciplinario en busca de un objetivo.

- Investigar puentes de identificación entre obra artística, creador y espectador.

- Situar obras y artistas en su contexto histórico.

- Utilizar el medio audiovisual como medio de fijación y desarrollo del pensamiento.

Si el ejercicio se realiza de forma adecuada podremos observar:

- La implicación de los alumnos en el proyecto.

- La pervivencia de los equipos de trabajo.

- Un cambio de actitud de los alumnos hacia las materias que se trabajan.

- Un cambio en la relación entre profesor y alumno.

- La importancia que tiene para el alumno el hecho de que su trabajo sea visionado, y el interés que su trabajo suscita fuera de la aula (éxito de asistencia en el visionado público posterior o en las descargas posteriores).

- Que alumnos conductuales y absentistas responden positivamente a la propuesta de trabajo.

- Que el análisis de los resultados de este ejercicio proporciona gran cantidad de información a los profesores tanto a nivel individual como del equipo de trabajo.

- Que los profesores que han participado en el proyecto han quedado satisfechos de los resultados y piensan repetir la experiencia. 
Imagen 14 - Metodología "Videolit". Esquema.

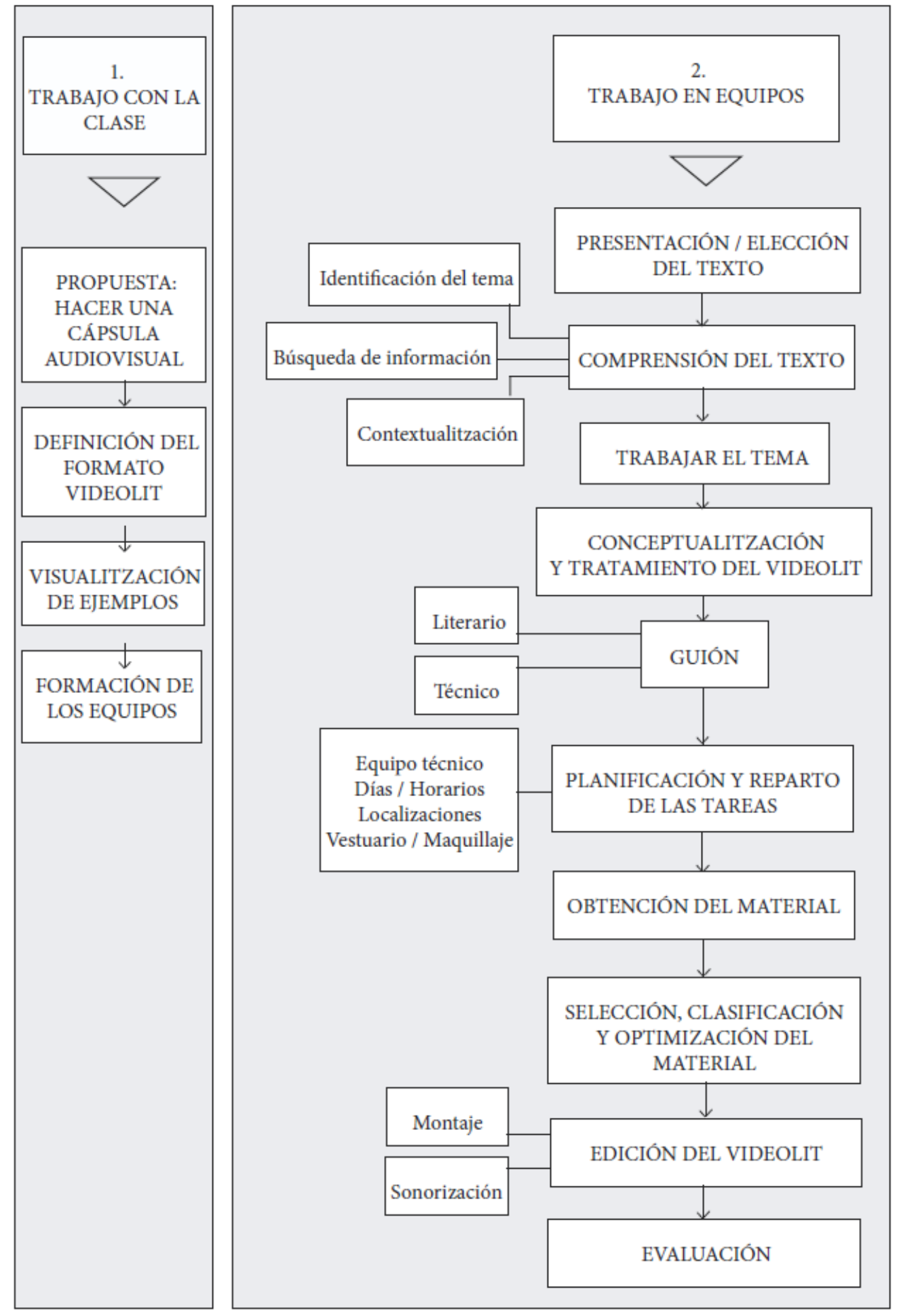

Texto Digital, Florianópolis, Santa Catarina, Brasil, v. 11, n. 1, p. 173-193, jan./jun. 2015. ISSNe: 1807-9288. 
Imagen 15 - Metodología "Videolit". Esquema.
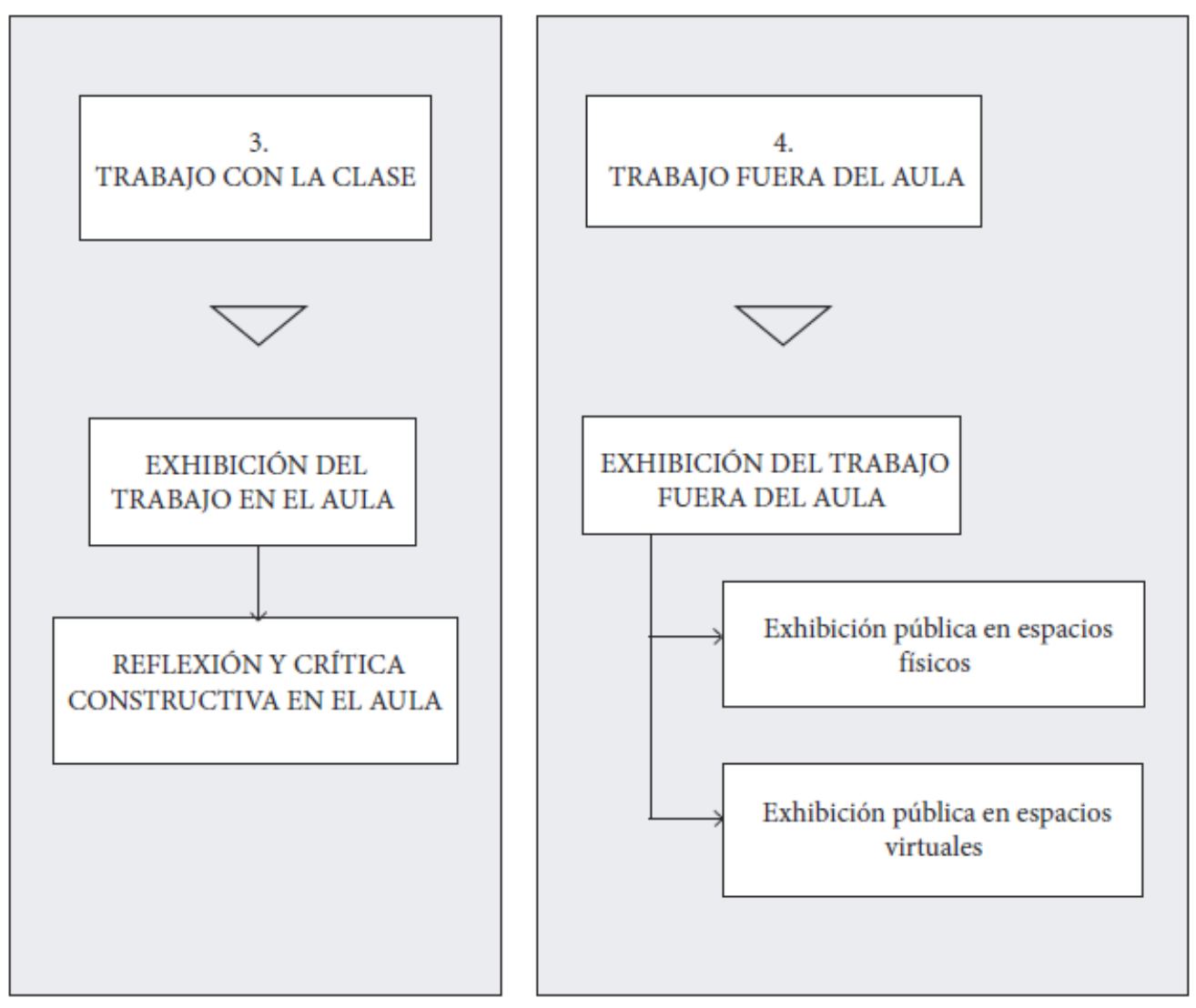

Durante el proceso, no podemos perder de vista, sin embargo:

- La importancia de tener en cuenta los conocimientos técnicos de los alumnos en función de la asignatura donde se utilice el formato.

- Las dificultades que suelen surgir entre diferentes departamentos de un mismo centro en el momento de colaborar en un mismo proyecto a pesar de la tan publicitada "transversalidad".

- La falta de tiempo para cumplir los programas educativos.

- La falta de formación en las TIC de gran parte del profesorado.

- La cómoda tendencia, por parte de los estudiantes, de recurrir a imágenes y música de la Red, con los tópicos que este hecho conlleva.

\section{Actualidad}

Actualmente, prevalece la velocidad, la no linealidad, y este cambio afecta a una actividad como la lectura y, por extensión, al sistema escolar, pero también a la 
creatividad en general. La historia se ha acelerado a un ritmo tan vertiginoso que los cambios son constantes y las instituciones (como la escuela) y las empresas sufren en el intento de adaptarse a esos cambios. Este dinamismo afecta tanto a la cultura como a la educación y el ocio. El profesorado no lo tiene fácil en las aulas pero no puede cerrar los ojos a estos cambios y debe intentar acercar el mundo real a la escuela. En este contexto, formatos como el videolit o el booktráiler tienen un largo camino por recorrer.

Imagen 16. Videolit "Así me siento a veces..."

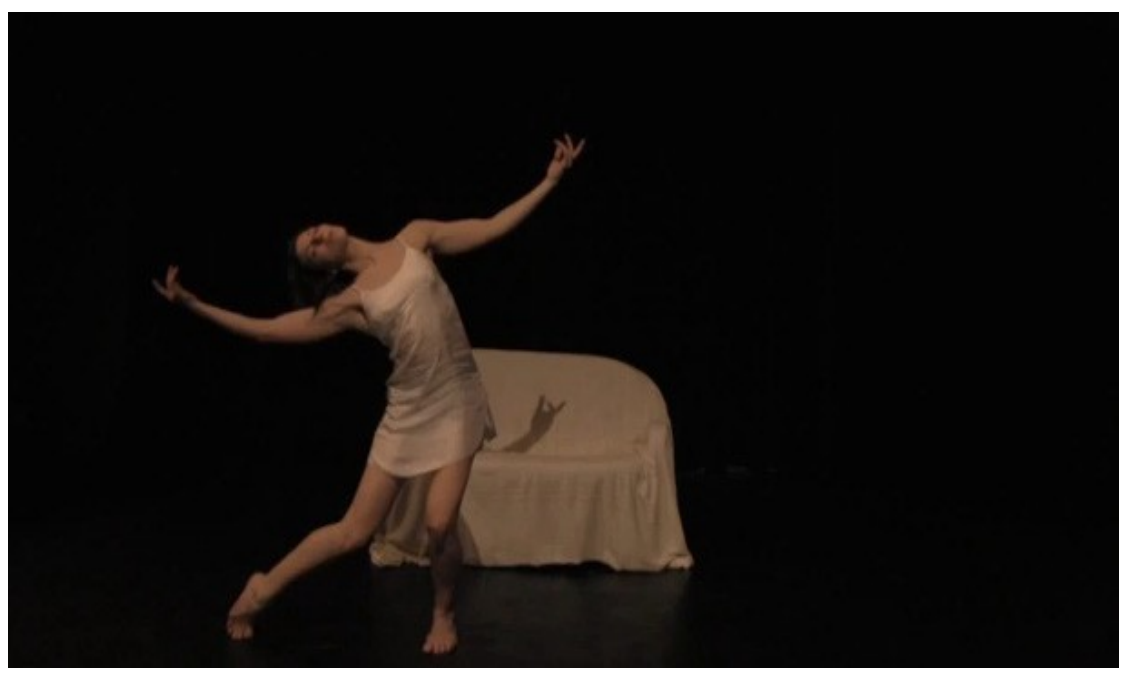

Las nuevas tecnologías cambian las metodologías, los procesos de aprendizaje $\mathrm{e}^{20}$, y el videolit y el booktrailer pueden ser dos buenos recursos para desarrollar la creatividad a través de la literatura. Lo hemos podido constatar participando en algunos proyectos de distintos centros educativos, congresos ${ }^{21}$, seminarios ${ }^{22}$,

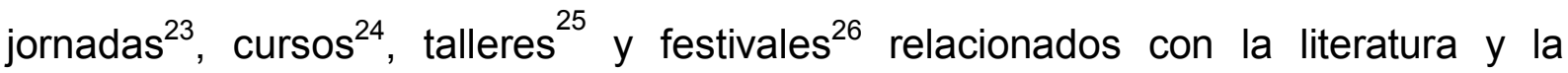

${ }^{20}$ Videolit realizado por Toni Gómez para la asignatura Videolit, impartida por A. Cort-C. Pedrola, en el apartado de "Las TIC y la educación" del "Màster de Literatura en la Era Digital" de la Universirtat de Barcelona.

${ }^{21}$ III Congrés d’Educació de les Arts Visuals Per a un diàleg entre les arts: "El videolit: 3 Dimensions, 1 Objectiu", A.Cort-C. Pedrola (Barcelona, 2009).

${ }^{22}$ Seminario La paraula pixelada, A. Cort-C. Pedrola. Organiza: ICE Serveis Educatius, Tarragona, 2008), Seminario LIT\&TIC: "LiTICteratura, videolit, ècfrasis i docència", A. Cort. Organiza Grup Hermeneia con el soporte de la UB (Universitat de Barcelona, 2011). Ciclo: La imatge: paradigmas $i$ cricuits del món medieval al postmedieval: "Imatge i paraula: Nous models d'exploració creativa", A. Cort. Organiza: Grup de Recerca EMAC-Juliols (Universitat de Barcelona, 2013).

${ }^{23}$ Jornadas: La recepció literària avui, una anàlisi des de la perspectiva dels gèneres: "Literatura, art i tecnologia", A. Cort (CERAP, 2012) IV Jornadas Pedagógicas: Les TIC en els espais museístics: "EI videolit: Una metodologia d'aprenentatge actiu a través d'un projecte de creació", A. Cort- C. Pedrola 
educación, siempre con buenos resultados.

La creación necesita formación (más allá de la intuición), y una buena formación requiere recursos informativos (bases de datos, obras de consulta, documentos), instruccionales (organizados con una intención formativa precisa), instrumentales (aportaciones interactivas que apoyan la aprendizaje, como pueden ser los blogs o las webs), experienciales (contenidos interactivos que favorecen el aprendizaje como pueden ser los juegos, los ejercicios de dramaturgia o de filmación), y conversacionales (chats y foros donde los contenidos los fijan los participantes), y pensamos que el videolit ${ }^{27}$ y el booktrailer pueden participar en todos ellos.

En la era digital ya no es suficiente con ofrecer libros y lecturas a lectores potenciales (aunque este punto sigue siendo fundamental). El rincón de las bibliotecas deberá ser ampliado progresivamente con todas las iniciativas que amplían las posibilidades de lectura y creación literaria: literatura electrónica ${ }^{28}$, literatura transmèdia, videolits, booktrailers... Es difícil concebir un mundo sin palabras, así es que, haremos bien en cuidarlas e incidir en su valor. El booktrailer y, especialmente, el videolit, pueden ser una buena herramienta para conseguirlo.

\section{A IMAGEN A SERVIÇO DA LITERATURA}

RESUMO: O artigo mostra o longo caminho feito até agora pela palavra e pela imagem através dos séculos para enfatizar a importância de conhecer a história como uma maneira de avançar até o futuro.

PALAVRAS-CHAVES: Palavra. Imagem. Tic. Videolit.

\footnotetext{
(Museu d'Art Modern de Tarragona, 2009).

${ }^{24}$ Màster: "El videolit com a recurs d'aprenentatge", Máster de Literatura en la era digital" (Universitat de Barcelona, 2009-2013) Curs TIC: "Booktràilers i videolits: la imatge al servei de la literatura" (Serveis Territorials a de Tarragona, 2014).

${ }^{25}$ Taller Transitar la paraula (Escola d'Art i Disseny de Tarragona, 2010), Taller Màster d'Estudis Superiors de Llengua, Literatura i Cultura Catalanes: "Videolit: Aprenentatge actiu a través d'un projecte de creació artística", A. Cort. Organiza Departament de Filologia Catalana de la Universitat Rovira i Virgili (Tarragona, 2013).

26 "Festival de Curtmetratges, FEC: El videolit: un nou format" (Reus, 2005), "V Festival de poesia de Reus": El videolit (Reus, 2010), Inauguració Cicle Obert: nous formats: "Videolit, un nou format". Centre de la Imatge de Reus amb la presentació amb la projecció de Ferrate(r): dos germans, dues mirades (Reus, 2006).

${ }_{27}^{27}$ Portal dedicado a la palabra imagen: <http://videolit.org/>.

28 "Look at me": <http://vimeo.com/10857606>.
} 


\section{IMAGES SERVING LITERATURE}

ABSTRACT: The article shows the long journey made so far by words and images through the centuries to emphasize the importance of knowing history as a way to move forward.

KEYWORDS: Word. Image. TIC. VideoLit.

\section{Referencias}

BARTHES, Roland. Variaciones sobre la escritura. Paidós Comunicación, 137 (Ed. Paidós, 2002).

BIRKERTS, Sven. Elegía a Gutenberg. El futuro de la lectura en la era electrónica (Alianza Editorial, 1999).

BLOOM, Harold. El futuro de la imaginación/ El futur de la imaginació. Col. Argumentos, 286 (Anagrama/Empúries, 2002).

BORRÀS, Laura. Textualidades electrónicas. Nuevos escenarios para la literatura. Ed. UOC. Barcelona, 2005.

"Digital Literatur and Theoretical Approaches", Laura Borràs (www.dichtungdigital.org/2004/3-Castanyer.htm).

CATALÀ, Josep M. La imagen compleja. La fenomenología de las imágenes en la era de la cultura visual (Col. Manuals, 42. Universitat Autònoma de Barcelona, 2005).

CORT, Aleix. Projecte Videolit. Paraula i imatge. Beca de la Entitat Autònoma de Difusió Cultural (2006).

CORT, Aleix y PEDROLA, Cori. És de nit que comença el dia (Col. la imatge que parla, 6. Arola Editors, 2000).

Discursos sobre arte digital: "Interacción entre la palabra y la imagen, proyección artística y posibilidades formativas: el videolit" Universidad de Màlaga, Eumed.net (Màlaga, 2012).

EXIT. "Escribiendo imágenes", 16. Revista online, Noviembre-Diciembre 2004-Enero 2005. Artículos, ensayos, conferencias y comunicaciones.

KRESS, Gunter y VAN LEEUWEN, Theo. Reading Images. The Grammar of Visual Dessign, Londres, Routledge, 1996. 
KRTU. Diversos autors. L'escriptura i el Ilibre en l'era digital (KrTU, Departament de Cultura de la Generalitat de Catalunya, 2006).

MARINA, José Antonio y DE LA VÁLGOMA, María. La magia de leer. DeBolsillo, 2007 (Random House Mondadori, 2005).

MOLAS, Joaquim. Manifestos d'avantguarda. Antologia. MOLU, 99 (Ed 62, 1995).

PHOTO TEXT TEXT PHOTO. The Synthesis of Photography and Text in Contemporary Art (Andreas Hapkemeyer \& Peter Weiermair, ed. Edition Stemmle.

PEDROLA, Cori. "Contribució de les representacions a la construcció del concepte de gènere a l'últim terç del segle XX" (Curs de Doctorat, "Art i Cultura en els media", UB 2005-2007).

ROVIRA, Jordi. "La enojosa lentitud de los libros” (La Vanguardia, Culturas 262)

SARTORI, Giovanni. "Homo videns". La sociedad teledirigida (Taurus, 1998).

TAPSCOTT, Don. Growing up digital. The rise of the new generation (McGraw-Hill. NY, 1998).

VOUILLAMOZ, Núria. Literatura e hipermedia. Paidós de Comunicación, 30 (Ed.

Paidós, 2000). 